\title{
Intelectualidad y racismo en Guatemala y El Salvador a finales del siglo XIX
}

Chester Urbina Gaitán

\section{Introducción}

Hacia mediados del siglo XIX, en Europa, surge la moderna teoría racista articulada sobre obras antropológicas de clasificación del género humano a partir de los conceptos biológicos de "especie" y "raza", desarrollados por los científicos desde el siglo XVIII. También tuvieron gran influencia los estudios que afirmaron la existencia de una supuesta raza aria y la teoría proveniente de los descubrimientos realizados por la lingüística del siglo XIX. En este sentido, destacan las propuestas de Comte, Darwin, Spencer, Gobineau, Le Bon, Mendel, Lombroso y de la eugenesia. El presente artículo pretende explicar por qué la regeneración física no incidió en el desarrollo de los pueblos indígenas en Guatemala y El Salvador a finales del siglo XIX.

\section{Guatemala}

En 1871 ascendió al poder en Guatemala un grupo de gobernantes de filiación liberal, que buscó crear el Estado-nación. Este proyecto político no tuvo una dimensión integradora, pues terminó por ser selectivo. Esta selección se hizo ladino e indígena por la lógica estatal de promover una "ciudadanización diferenciada" entre la población. ${ }^{1}$ Es palpable el interés estatal en transformar a los trabajadores urbanos y sus redes de poder ladina e indígena rurales en sustento de apoyo a su ideario.

Aunque teóricamente la principal herramienta de construcción de la hegemonía ha sido la política de educación pública. ${ }^{2}$ La política de educación estatal en Guatemala no tuvo como objetivo trastocar las costumbres de los sectores subalternos. Debido a que el régimen de trabajo forzado imposibilitó a los sectores indígenas el acceso a la educación; y, cuando la tenían, era en 
escuelas para indígenas, especializándose en una educación campesina. Por el contrario, el trabajo si desempeñó un claro papel como medio de coacción y control social y, por lo tanto, de constructor y reproductor de visiones y realidades hegemónicas.

Es durante el período liberal que se origina un proceso de asimilación cultural al proyecto nacional ladino promovido por el Estado. Al respecto, Taracena y colaboradores aportan que dicho proceso estaba minado por una realidad segregatoria desde el momento en que la producción de la riqueza agrícola del país se basaba en el trabajo forzado de los indígenas. Además, los indígenas debían lidiar con otro elemento que socavaba su proceso de asimilación, el del discurso ideológico que, aparte de "bárbaros", los designaban como producto de una "degeneración" histórico-cultural, que se manifestaba en la humillación, la embriaguez, la criminalidad, la idiotez y la suciedad. Esto justificaba su condición de trabajadores forzados y la imposición de su tutela ciudadana por parte del Estado, dando como resultado una ciudadanía diferenciada. ${ }^{3}$

Sobre el racismo en Guatemala durante el período liberal Marta Casaús señala que es ahí cuando el racismo empieza a operar como racialismo, valorando las diferencias biológicas y raciales en lugar de las diferencias culturales o sociales. El imaginario racista se modifica sustancialmente por la influencia del liberalismo, el positivismo y el darwinismo social, y empieza a operar como un fuerte mecanismo de diferenciación política y social al producirse la transición de una sociedad de casta a una sociedad de clases, de un Estado corporativo estamental a un Estado constitucional basado en la igualdad entre los ciudadanos y ante la ley, donde se hacía necesario crear nuevos mecanismos que permitieran mantener la diferencia como desigualdad, la desigualdad como discriminación y esta como explotación. ${ }^{4}$

En 1888 aparece publicado, en la ciudad de Guatemala, el libro del salvadoreño Francisco Esteban Galindo Elementos de Pedagogía, donde señala que, de los tres millones de habitantes que pueblan Centroamérica - no contando las tribus errantes - millón y medio son indígenas. El autor también apuntaba que el día en que se civilizaran esos hijos primogénitos de la tierra centroamericana, la nación habrá duplicado sus fuerzas vivas y sería arrebatada por un vértigo de progreso. ${ }^{5}$

Para Galindo el pueblo indio y el ladino son dos pueblos superpuestos el uno sobre el otro; los medios civilizadores tienen que ser diferentes, tratándose de 
una o de otra masa social, so pena de que los medios generales sean, en uno u otro sentido, ineficaces. ${ }^{6}$

El poco impacto de la educación en los indígenas radicaba en que los padres indígenas querían que sus hijos se les parecieran en todo, amando con entrañable amor sus costumbres, como tradición sagrada de sus mayores. Los padres indígenas comprendían que en la escuela los niños se aproximaban sin sentir al modo de ser de la otra raza, y se conjuran contra la asistencia de sus hijos a los planteles de enseñanza. ${ }^{7}$

Así mismo, Galindo acota que la embriaguez — pasión dominante entre la raza indígena - era una barrera con la que tenía que enfrentarse el maestro. El indio enseñaba a beber a sus hijos; y cuando esto no sucedía, el niño, al crecer, adoptaba el vicio de sus padres y la enseñanza quedaba esterilizada. ${ }^{8}$

En 1899 el Dr. Darío González, de origen salvadoreño, saca a la luz Nociones de Pedagogía en pequeñas lecciones. El libro estaba destinado a servir de texto en los establecimientos de enseñanza. Fue premiado con diploma y medalla de oro por el Gran Jurado de la Exposición Centroamericana de 1897. Esta obra había sido publicada por primera vez ese año en el periódico de la Escuela Normal de Señoritas de Guatemala. Las lecciones fueron redactadas para las alumnas de aquella institución, en vista de la carencia de un texto propio para la enseñanza elemental de la Pedagogía.

González resaltaba que la necesidad de la educación física era evidente, ya que por su medio se conservaba y mejoraba la salud, haciéndose así el cuerpo fuerte, robusto, ágil y apto para toda clase de trabajos, sin exceptuar los intelectuales. ${ }^{9}$ Pese a estas ideas, el autor nunca expuso la necesidad de que el mundo indígena guatemalteco se beneficiara de la práctica del deporte y de la educación física.

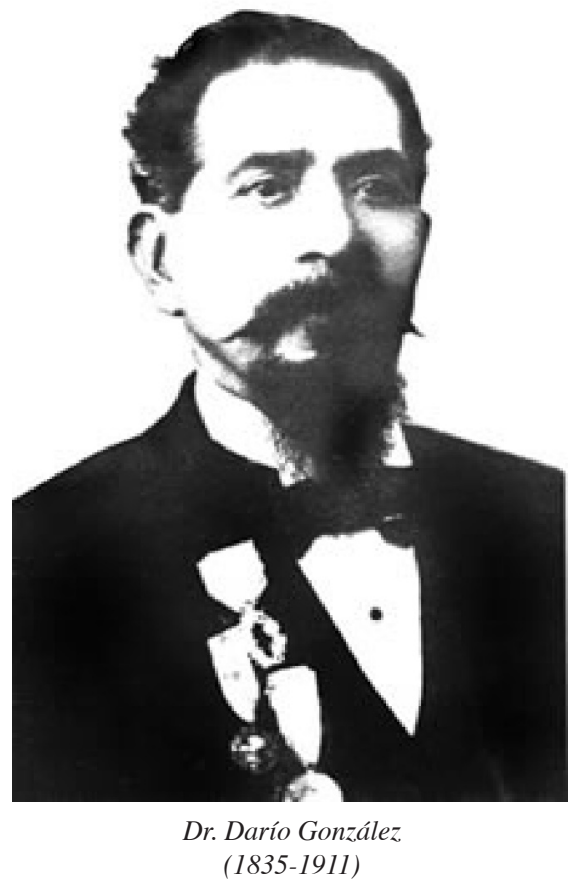




\section{El Salvador}

A fines del siglo XIX los intelectuales salvadoreños que trabajaban para el Estado trataron de promover un proyecto de nación sustentado en el pensamiento europeo de la época, que los llevó a compartir la fe en el progreso, así como al rechazo a la tradición cultural indígena, considerada como muestra de atraso $y$, en consecuencia, un freno al desarrollo. ${ }^{10}$

Uno de los más destacados intelectuales de esta época fue Francisco Gavidia, quien se encargó de realizar una reelaboración literaria del pasado precolombino. ${ }^{11}$ Pese a la formulación de esta mitología indígena, los liberales salvadoreños prefirieron elaborar otros mitos más acordes con sus ideales. En realidad, el discurso dominante fue aquel que propugnaba por la modernización y el progreso. Los mitos indígenas a lo sumo podrían ser aceptados como accesorios, pero no iban a ser incorporados como parte fundamental de la cultura.

En 1883 el Dr. David Joaquín Guzmán publicó su libro Apuntamientos sobre la topografía física de la República de El Salvador. En este texto el médico señala que la migración es el medio más eficaz, pronto y seguro del mejoramiento de las razas, la rehabilitación del sistema de gobierno, la fuente más vasta de prosperidad material y la más sólida, fácil y fecunda esperanza del acrecentamiento de la riqueza pública. ${ }^{12}$ También acota que los indios no se mezclan con los blancos y ladinos, resistiéndose a comunicar cualquier cosa sobre su forma de vida. ${ }^{13}$

Para Guzmán los indígenas salvadoreños eran menos civilizados que sus antecesores, y recelaban aquello que se les presentaba como una innovación. ${ }^{14}$ Termina Guzmán planteando la inquietud sobre cuál es el porvenir de la raza india en el país y su definitiva metamorfosis, a lo que responde diciendo que su única alternativa era ser parte de la vida social y de la escuela. ${ }^{15}$

En torno a esto, López señala que, en la medida en que los patrones culturales tradicionales eran incompatibles con el proyecto modernizante de la elite se hacía necesaria la imposición. A Guzmán no le interesó preguntarse cuáles eran los intereses de los indígenas, más creía que al final estos serían beneficiados al ser absorbidos por el mestizaje, borrando de ese modo las antiguas diferencias. ${ }^{16}$ 


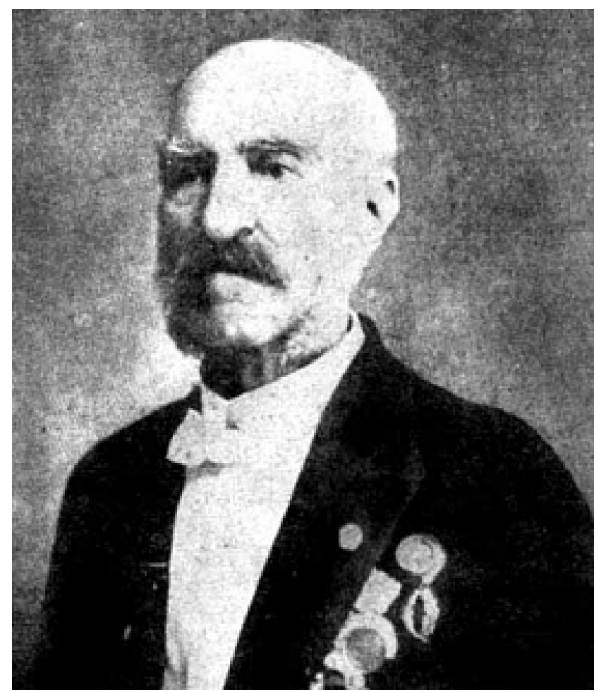

Dr. David Joaquín Guzmán Martorell (1843-1927)

Según Georgina Hernández las posturas racialistas de intelectuales como Guzmán, a pesar de no concretarse en un racismo práctico, sí ejercieron un papel simbólico en el ejercicio del racismo al mantener la idea de una jerarquía social racialmente diferenciada, en la cual el blanco detentaba la escala mayor y gozaba de un papel director frente a las minorías, a las que creía atrasadas, feas, y apáticas. Estos juicios de valor tenían una carga negativa que permitió la generación de estereotipos, que fueron instrumentalizados para poner de relieve la dominación y la inferiorización. Guzmán fue uno de estos intelectuales influidos por el pensamiento racialista, y que se veían a sí mismos como parte del grupo blanco que debía llevar las riendas del país: su poder lo ejerció desde cargos públicos y a través de la política, desde donde impulsó proyectos de regeneración del indígena a partir de la educación. ${ }^{17}$

\section{Conclusión}

La implantación de una ciudadanía diferenciada y el apego a posturas racistas hacia lo indígena llevo a los Estados guatemalteco y salvadoreño a no permitirle el acceso a la modernidad y la regeneración física a través de la práctica del deporte y la educación física a finales del siglo XIX. Así mismo, la idea de regenerar a los indígenas a través de la educación no se concretó debido al poco apoyo y a la fragilidad económica de la hacienda pública. En la práctica los indígenas quedaron al margen del proyecto liberal de nación, dejándolos sin fundamento cultural.

\section{Referentes bibliográficos}

1 En este sentido es necesario la consulta a: Taracena Arriola.Arturo, et.al. Etnicidad, Estado y nación en Guatemala 1808-1944. Guatemala: Nawal Wuj, 2002. Asimismo véase: 
Piel, Jean. “¿Fuera el Estado del Estado? ¿Afuera la nación? El Quiché oriental frente al Estado-nación guatemalteco de 1821 a 1970”. En: Taracena A., Arturo y Piel, Jean. Identidades nacionales y Estado moderno en Centroamérica. San José: Editorial de la Universidad de Costa Rica, 1995. p.188. En la misma línea Little-Siebold apunta que, el Estado guatemalteco por su fragilidad económica no pudo tener un fuerte control social de la población. Little-Siebold, Todd. "Guatemala en el período liberal: patria chica, patria grande. Reflexiones sobre el Estado y la comunidad en transición”. En: ibid. pp.223-236. También: Taracena Arriola, Arturo. Invención criolla, sueño ladino, pesadilla indígena. Los altos de Guatemala: de región a Estado, 1740-1871. Antigua: Editorial Porvenir S.A.Cirma, 1997; y, Little-Siebold, Todd. "La centrifugación del Estado: sueños centralistas, realidades locales. Formación, deformación y reformación del Estado guatemalteco, 1871-1945”. En: Piel, Jean y Little-Siebold, Todd. Entre comunidad y nación. La historia de Guatemala revisitada desde lo local y lo regional. Antigua: Cirma, 1999. pp.143-165.

2 González Orellana, Carlos. Historia de la educación en Guatemala. Guatemala: Editorial Universitaria, 1987.

3 Taracena Arriola, Arturo, et.al. Etnicidad, Estado y nación en Guatemala 1808-1944. Guatemala: Nawal Wuj, 2002. p.37.

4 Casaús Arzú, Marta Elena. "Prácticas sociales y discurso racista de las elites de poder en Guatemala (Siglos XIX y XX)". En: Van Dijk, Teun. Racismo y Discurso en América Latina. Barcelona: Gedisa, 2007. p.233.

5 Galindo, Francisco E. Elementos de Pedagogía. Guatemala: Tipografía La Unión, 1888. p.49.

6 Idem.

7 Ibid. p.50.

8 Idem.

9 González, Darío. Nociones de Pedagogía en pequeñas lecciones. Segunda edición. Guatemala: Tipografía Nacional, 1899. p.19.

10 Algunos de los más destacados intelectuales de la época fueron los siguientes: Darío González, Jorge Lardé, Santiago I. Barberena, Alberto Sánchez, David J. Guzmán, Pedro Fonseca, Rafael Reyes, Antonio Cevallos, Vicente Acosta y Francisco Gavidia.

11 Hernández Aguirre, Mario. Gavidia. Poesía, literatura y humanismo. San Salvador: Dirección de Publicaciones, Ministerio de Educación, 1968. p.389.

12 Guzmán, David Joaquín. Apuntamientos sobre la topografía física de la República de El Salvador. San Salvador: Tipografía El Cometa, 1883. p.446.

13 Ibid. p.500.

14 Ibid. p.501.

15 Ibid. p.517.

16 López Bernal, Carlos Gregorio. "La historia cultural en El Salvador: Un campo de estudio en ciernes”. En: Marín Hernández, Juan José; Vega Jiménez, Patricia y Cal Montoya, José Edgardo. La historia cultural en Centroamérica: Balance y perspectivas. Guatemala. Cefol-Usac, 2006. p.53.

17 Hernández Rivas, Georgina. "David J. Guzmán: la institucionalización del discurso racista en las elites simbólicas del poder”. En: Asociación para el Fomento de los Estudios Históricos en Centroamérica. Boletín No.41. http://afehc-historia-centroamericana.org/index.php?action=fi_aff\&id=2222 


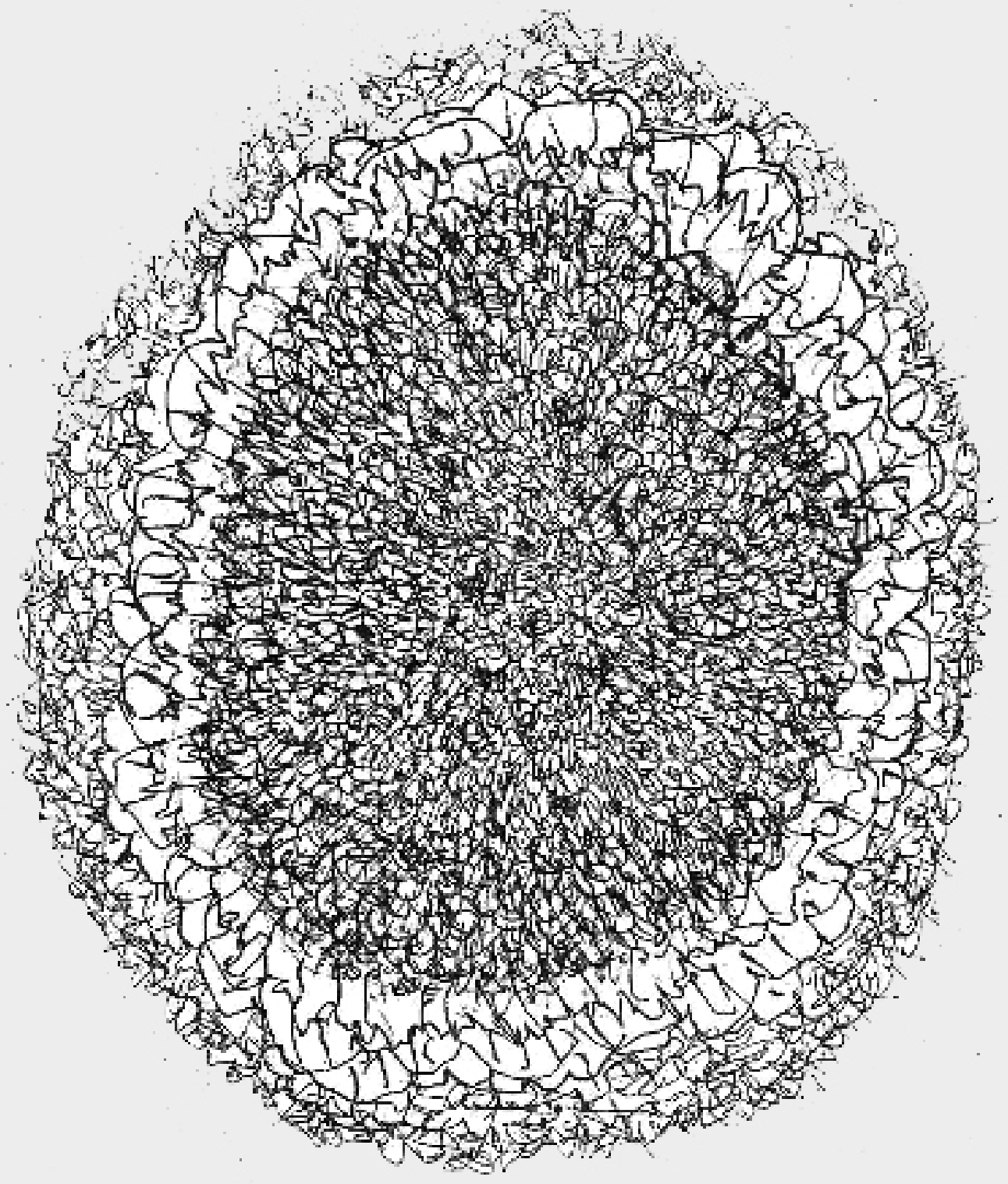




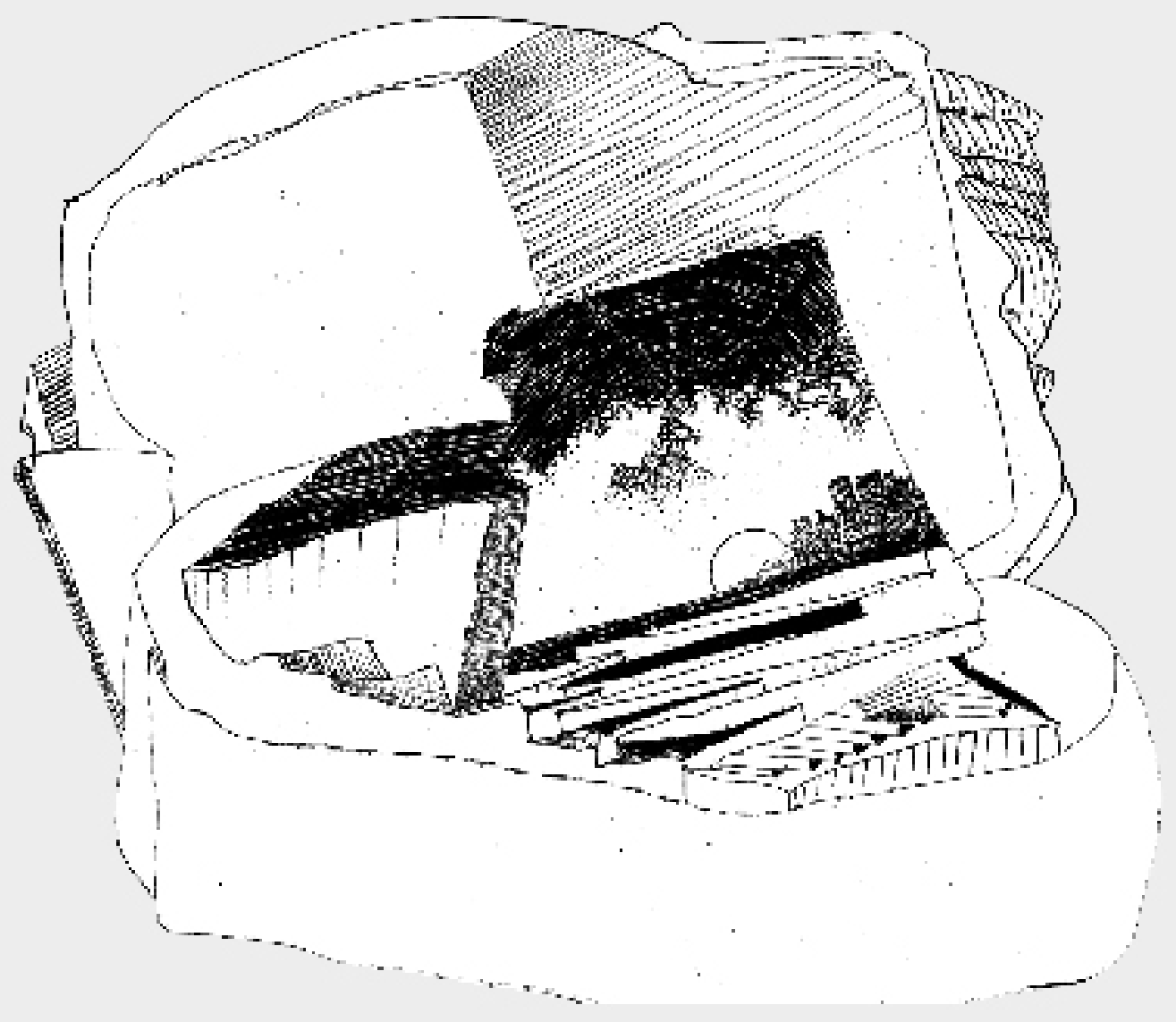

